\title{
Redisplacement Rates after Reduction and Cast Immobilization of Isolated Distal Radial Fractures
}

Ojuka D. MBChB, MMed ${ }^{1}$, Ating'a J. MBChB, MMed, MCh (Orth) ${ }^{2}$ Afilliation: 1-Kapenguria district hospital 2- Department of orthopaedic surgery, Univesity of Nairobi. Correspondence: Dr. Daniel Ojuka, Kapenguria district hospital, P.0. Box 63 - 30600, Kapenguria, Kenya. E-mail: dkinyuru@yahoo.com

\section{Abstract}

\author{
Background \\ The maintenance of satisfactory alignment in distal radial fractures \\ following closed reduction and casting of the forearm is challenging. \\ Redisplacement rates of between 2 and $91 \%$ have been described, \\ mostly for Western populations and for fractures involving both the \\ forearm bones. The local scenario is unexplored. \\ Objective \\ This study sought to determine the rate of redisplacement in isolated \\ closed distal radial fractures in children aged 6-15 years and the fac- \\ tors contributing to the redisplacement. \\ Setting \\ The Kenyatta National Hospital, a teaching and referral hospital in \\ Kenya.

\section{Patients and Methods} \\ This was a prospective study carried out between June 2005 and \\ February2006. Patients were recruited from casualty, where the \\ fracture was reduced and casted. Immediate check x-rays were taken \\ to ascertain satisfactory alignment. At follow up the fractures were \\ evaluated for redisplacement in the fracture clinic in the second and
}

fourth weeks with further check $x$-rays. Redisplacement was regarded as the presence of dorsal or volar-angulation of greater than $20^{\circ}$. The data was collected and entered into statistical package for social sciences (SPSS) 12.0 version. Comparison of the binomial outcomes of the factors determining the redisplacement of the distal radial fractures was carried out using Fischer's exact test. P value $<0.05$ was taken to be significant.

Results

Ninety-two patients were evaluated. Overall redisplacement rate was $15.7 \%$. Factors significantly associated with redisplacement included initial displacement, completeness of fracture and non-satisfactory initial reduction.

\section{Conclusion}

The rate of redisplacement of $15.7 \%$ reported here is within the range that is considered acceptable. The success of re-manipulation at the $\mathrm{KNH}$ is unsatisfactory. Percutaneous K-wiring should be considered for those with complete fractures with displacement that do not achieve perfect reduction at initial check radiographic film.

\section{Introduction}

Distal radius fractures are common injuries in children and affects boys more than girls (1). Isolated distal radial fractures can result from indirect trauma involving angular loading combined with rotational displacement. Traditionally, these fractures have been treated by closed reduction and immobilization in a plaster cast. This method of treatment is however associated with various rates of redisplacement and malunion (1-5), especially for fractures involving both the ulna and the radius and not the latter in isolation.

Reports from the West and East indicate that success of the reductions, performed by surgeons and orthopaedic residents, is influenced by the initial displacement, presence of ipsilateral ulnar fracture, amount of cortical disruption and type of analgesia the reduction is performed under as well as how well the fracture is reduced $(3,6)$.
It is unclear whether similar results obtain in our set up, where reduction and casting are performed by plaster technicians. This study sought to determine the rate at the KNH and factors affecting redisplacement after reduction and casting.

\section{Patients and Methods}

\section{Design:}

This was a prospective hospital based study that was carried out between June 2005 and 2006.

The patients were recruited from the $\mathrm{KNH}$ casualty department. The inclusion criteria included closed isolated radial metaphyseal fracture, age 6-15 years and consent from the parents of the patients who presented themselves within $24 \mathrm{hrs}$ of injury. The patient's demographic data and parent's socioeconomic status (low socioeco- 


\section{Redisplacement Rates after Reduction and Cast Immobilization of Isolated Distal Radial Fractures}

nomic status were those earning less than $\$ 125$, while middle those who earn \$125-375 per month) were recorded as well as the characteristics of the fracture such as displacement (angulations, translations, direction of displacement) and completeness from the initial radiographic film. The reductions were performed by plaster technicians under sedation for all the patients, as is the standard procedure at the institution, after which check radiographic films were reviewed to assess for adequacy of reduction. All the casts were short arm casts in the manner described by Charnley (7). Because this was an observational study, the technicians were not particularly trained for any type of reduction or cast other than the ones they do for these types of fractures (i.e. complete casts). The initial check radiograph after reduction was used to assess the adequacy of reduction and those which were not satisfactorily reduced were immediately remanipulated under sedation.

The patients were reviewed the following day to check on swelling or check films if not available on the day of reduction at the fracture clinic. Follow up was done in the second and fourth week for all the patients in the fracture clinic. Those who had fracture redisplacement during reviews at second week were remanipulated under sedation. Those whose fractures showed signs of redisplacement at four weeks were admitted for operative reduction. Redisplacement was regarded as the presence of dorsal or volar angulation of greater than $20^{\circ}$. This was estimated using a protractor due to the unavailability of goniometer.

\section{Number}

$\%$

\section{Completeness}

\begin{tabular}{lll}
\hline Incomplete & 34 & 37 \\
\hline Complete & 58 & 63 \\
\hline Displacement & & \\
\hline Non & 53 & 57.6 \\
\hline Displaced & 39 & 42.4 \\
\hline Reduction & & \\
\hline Imperfect & 19 & 48.7 \\
\hline Perfect & 20 & 51.3 \\
\hline
\end{tabular}

Table 1. Distribution by fracture characteristics

\section{Results}

Of the one hundred children recruited into the study, 92 had isolated metaphyseal radial fractures. Fifty-nine (64.1\%) were male, fifty-two (56.5\%) were aged below 10 years, and forty-one (44.6\%) were of low economic status. The proportion of fractures that were complete, displaced and perfectly reduced was $63 \%(58), 42.4 \%$ (39), and $51.3 \%(20, \mathrm{n}=39)$ respectively (Table 1$)$.

During the evaluation at two weeks, 83 of the 92 patients presented for follow up assessment. According to the check radiographic films reviewed, $15.7 \%$ (13) of the fractures were redisplaced.

In the fourth week, 76 patients were available for follow up evaluation (71 of these were part of those evaluated at two weeks). Only the 71 consistent patients were therefore used in analysis. The proportion of the group that had redisplacement was $15.7 \%$.

The demographic characteristics of the patients did not significantly influence redisplacement. The fracture characteristics significantly influenced redisplacement with $P$ values of $<0.001$ for displacement, 0.003 for completeness of fracture and 0.028 for whether or not the reduction was satisfactory (Table 1).

\section{Discussion}

Although the traditional treatment of distal radial fracture by reduction and immobilization in a cast is associated with good functional results $(8,9)$, loss of reduction in the cast is a well-documented problem $(8,9)$. The quoted rate of redisplacement ranges from 2 to $91 \%$ ( 1 , $3,8,9,10,11)$.

In this study, we considered only isolated radial fractures. The displacement rate of $15.7 \%$ after four weeks of follow up is within the range of most of the quoted studies. Gibbon et al prospectively evaluated 12 patients with isolated radial fractures and reported a remanipulation rate of $91 \%$ by the time of union. Only two patients seemed to have had successful remanipulation in the current series. Eleven out of the 13 needed operation. The success rate for our remanipulation seems inferior to those of Gibbon et al (10). A consideration for percutaneous $\mathrm{K}$ wiring may be required as the primary treatment where the risk of redisplacement is high.

Remanipulation was performed in the second week in our study. Previous studies have reported successes up to day 24 post- fractures $(10,11)$ with rates in their study of 
$7 \%$, probably due to their aggressive nature in remanipulation.

The risk factors that have been considered to be significant in contributing to redisplacement in other studies have been initial displacement and failure to achieve perfect reduction $(9,3,11,13)$. The initial displacement includes angulations and direction of displacement. The significant factors in the current study were similar to these. Demographic and socioeconomic variables did not have any effect.

This study was limited by the number of patients lost to follow up. Ten percent of the patients were lost by two weeks and only $77.2 \%$ were available for evaluation at four weeks. Further limitations included the lack of instruments such as goniometer and the observational nature of the study. Plaster technicians were utilized in this study, a design substantially different from other reported studies where orthopaedic surgeons and residents performed the manipulations.

We conclude that the rate of redisplacement is significant but within the range that could be considered acceptable. However, our results of remanipulation were poor. Percutaneous K-wiring should be considered for those with complete fractures with displacement.

\section{References}

1. Dickie TE. Nunely JA. Distal forearm fractures in children. Complications and surgical indications. Orth Clin N Amer 1993; 24:333 -9

2. Kholsa S, Melton LJ, Dekutoski MB, et al: Incidence of childhood distal forearm fractures over 30 years: A population based study. JAMA 2003; 290:1479-86

3. Zamzam MM. and Khoshhal K. I. Displaced fracture of the distal radius in children; factors responsible for redisplacement after closed reduction. J Bone Joint Surg (Br) 2005; 87-B: 841-3.

4. Freiberg K.S.I. Remodelling after distal forearm fractures in children. III. Correction of residual angulation in fractures of radius.Acta Orthop Scand1979c; 50:741-9.

5. Gavin R.W., Robert D.G, Douglas G.A. Comparison of short and long arm plaster casts for displaced fractures in the distal third of the forearm in children. J Bone Joint

\begin{tabular}{llll} 
Factor & Displaced & Not displaced & P-value (*Fischer's) \\
Age & & & \\
\hline $6-10$ & 6 & 40 & 0.333 \\
\hline $11-15$ & 7 & 30 & \\
\hline Gender & & & \\
\hline Male & 10 & 42 & $0.201^{*}$ \\
\hline Female & 3 & 28 & \\
\hline Parents socioeconomic status & & & \\
\hline Low & 5 & 28 & \\
\hline Middle & 8 & 42 & \\
\hline Fracture Completeness & & & \\
\hline Incomplete & 0 & 28 & \\
\hline Complete & 13 & 42 & $0.003^{*}$ \\
\hline Displacement & & & \\
\hline Non displaced & 1 & 46 & \\
\hline Displaced & 12 & 24 & $0.001^{*}$ \\
\hline Reduction & & 12 & \\
\hline Non satisfactory & 5 & & \\
\hline Satisfactory & 8 & & \\
\hline & & & \\
\hline
\end{tabular}

2: Predictors of redisplacement at 2 weeks

Surg (Am) 2006; 88-A: 9-17

6. Hughston J. C. Fractures of the forearm in children. J Bone Joint Surg (Am) 1962; 44-A: 1678-93.

7. Charnley J. The closed treatment of common fractures. 4th ed. Cambridge: Colt; 1999

8. Fuller DJ, Mc McCullough CJ, Malunited fracture of the forearm in children. J Bone Joint Surg (Br) 1982; 64: 364367.

9. Proctor MT, Moore DJ, Paterson JMH. Redisplacement after manipulation of distal radial fractures in children. J Bone Joint Surg (Br) 1993; 75-B: 453-4.

10. Gibbons C, Woods DA, and Pailthorpe J. The management of isolated distal radius fractures in children. J Pediatric Orthop1994. 14(2): 207-210.

11. Davis DR, Green DP. Forearm fractures in children: Pitfalls and complications. Clin Orthop 1976; 120: 172-180

12. Voto SJ, Weiner DS, and Leighley B, Redisplacement after closed reduction of the forearm fractures in children. J Pediatr Orthop 1990; 10(1): 79-84

13. Mclauchlan GJ, Cowan B, Robb JE, Annan IH. Management of completely displaced metaphyseal fractures of the distal radius in children. J Bone Joint Surg (Br) 2002; 84B: $413-7$ 